\title{
Posttraumatic Giant Macular Hole
}

\author{
Sergio E. Hernandez-Da Mota \\ Clinica David, Unidad Oftalmologica, Morelia, México
}

\section{Key Words}

Trauma - Giant macular hole

\begin{abstract}
Introduction: Large macular holes secondary to blunt trauma are sometimes seen in young patients within the spectrum of alterations produced by ocular trauma.

Methods: Observational case report. A 32-year-old woman who had received a blunt trauma (a blow from a fist) to her right eye 10 years previously had experienced a decrease in visual acuity ever since.

Results: Clinical photographs, fluorescein angiography and optic coherent tomography images revealed a very large macular hole of approximately 1,920 $\mu \mathrm{m}$ in diameter.

Conclusion: This case is an uncommonly large variant of a macular hole secondary to blunt trauma in a young patient.
\end{abstract}

\section{Introduction}

A macular hole secondary to trauma is an entity that is present as part of the spectrum of manifestations of blunt ocular trauma. It usually occurs in young patients and can be associated with other changes, such as the presence of choroidal ruptures, Berlin's edema and retinal pigment epithelium atrophy. The size of these holes may vary, although those that exceed $1,500 \mu \mathrm{m}$ in diameter are very rare [1].

\section{Case Report}

A 32-year-old female patient had a 10-year history of decreasing visual acuity after blunt ocular trauma from a fist blow to her right eye. No other intercurrent general disease was reported by the patient. The best-corrected visual acuity was 5/400 in the right eye and 20/20 in the left eye. The intraocular pressure was $16 \mathrm{~mm} \mathrm{Hg}$ in both eyes. The anterior segment of each eye was normal, without the presence of angle recession or iridodialysis.

Sergio E. Hernandez-Da Mota, MD Blvd. García de León 598 


\section{Results}

In the posterior pole, a macular hole that was larger than one disc diameter and epipapillary fibrosis were documented (ig . 1 ). The left eye fundus was normal. Fluorescein angiography showed a circular hyperfluorescent window defect that extended beyond the edges of the macular hole seen in the clinical picture (fig. 2). Optical coherence tomography showed the presence of a full-thickness macular hole approximately $1,920 \mu \mathrm{m}$ in diameter (fig. 3).

\section{Discussion}

Macular holes have multiple causes and etiologies. The most common type is idiopathic, occurring in women between the 6 th and 7 th decade of life. Treatment usually includes vitrectomy with the removal of the internal limiting membrane. Several methods have been described for this purpose, including impregnation with different dyes.

Macular hole secondary to trauma may occur at any age. It is most often seen in male patients between the 2 nd and 4 th decade of life. Traumatic macular holes are produced by a sudden increase in tangential traction vector forces in the vitreous cortex and exerted on the macular area. They are usually associated with other common alterations, such as choroidal ruptures, contusions of the retinal pigment epithelium and subretinal hemorrhages.

The diameter of most holes tends to be between 400 and $750 \mu \mathrm{m}$ in stage 4 macular holes, but Sjaarda and Thompson [1] have reported extreme diameters of 300-1,500 $\mu \mathrm{m}$. Macular holes larger than $1,500 \mu \mathrm{m}$ are very rare and might be referred to as giant macular holes. These larger macular holes are more often attributed to blunt trauma than to other clinical entities, but associations with other conditions, e.g. Alport's disease [2], have been reported.

The size of the hole is most closely related to the mechanism of trauma - specifically, where the main vectors of tangential force at the moment of impact on the macula were greatest and most rapid. In our patient, the force of the blow combined with the very low degree of vitreous syneresis and synchysis typical of a young person rendered the separation area more prone to enlargement, thus producing a larger macular hole.

The treatment for idiopathic macular holes is essentially the same as for posttraumatic holes. There are, however, reports of spontaneous closure without the need for surgery [3]. In the case of our patient, the decision not to operate was based on the long duration of the hole's presence, the extensive atrophy of the retinal pigment epithelium (extending even beyond the edges), and the large size of the hole. These factors indicated a low likelihood of successful closure [4]. In addition, the patient declined to undergo surgery because of the poor outlook for anatomical and functional improvement.

This case is an uncommonly large variant of a macular hole secondary to blunt trauma in a young patient and adds new information as to how large macular holes can get, especially posttraumatic ones. 


\section{Disclosure Statement}

The author declares that no competing interests exist.

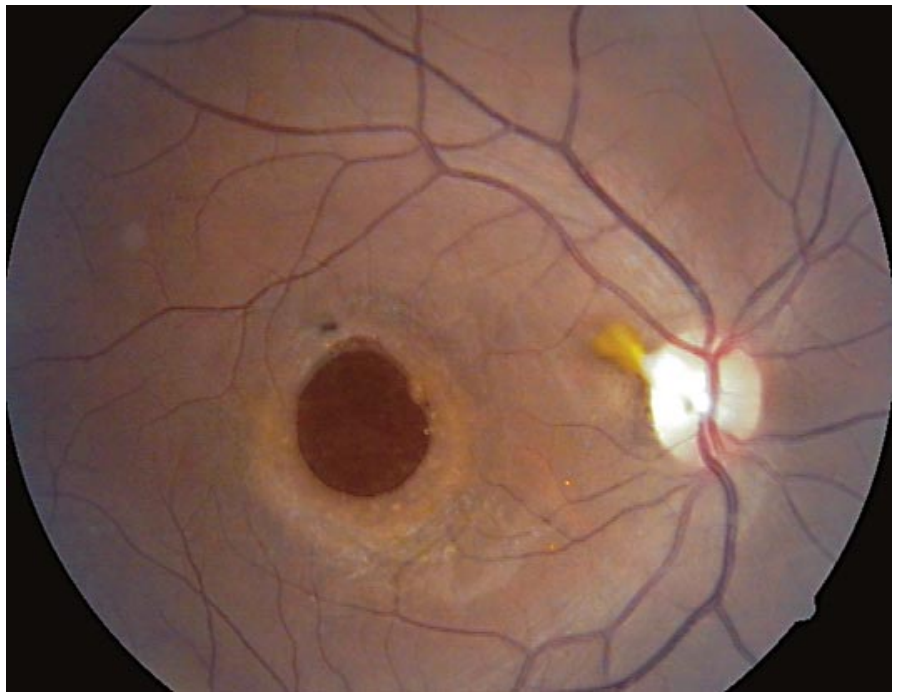

Fig. 1. Clinical picture of the macular hole.

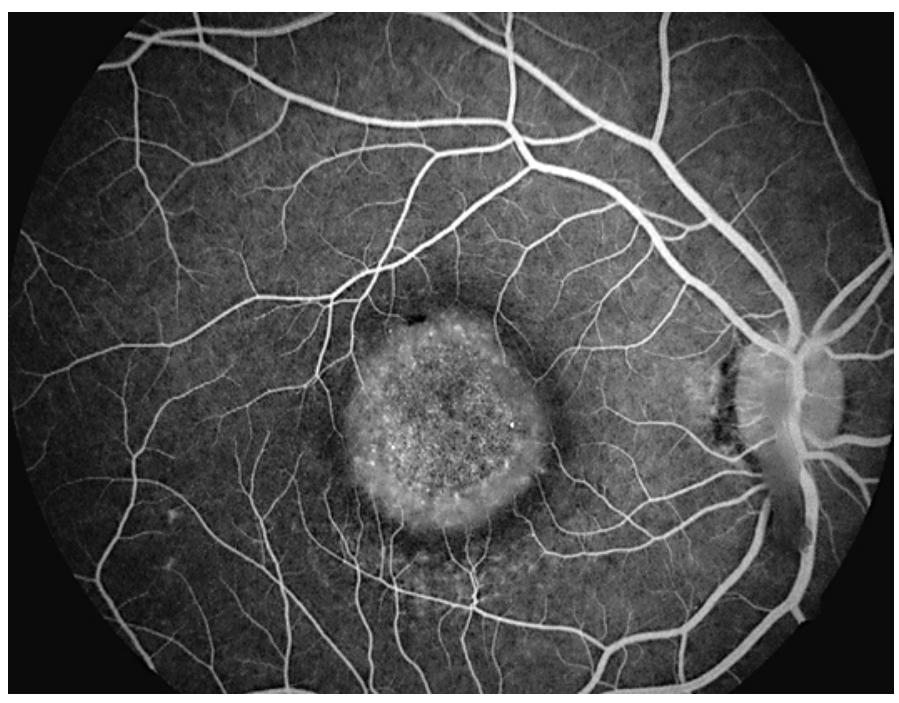

Fig. 2. Fluorescein angiogram of the large macular hole. 


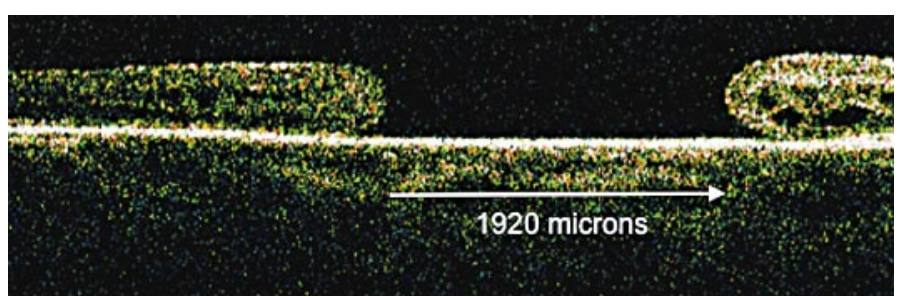

Fig. 3. OCT linear scan image showing the size $(1,920 \mu \mathrm{m})$ and full thickness of the macular hole.

\section{References}

1 Sjaarda RN, Thompson JT: Macular hole; in Wilkinson CP (ed): Ryan's Retina. St. Louis, Mosby-Elsevier, 2006, vol 3, pp 2527-2544.

2 Shah SN, Weinberg DV: Giant macular hole in Alport syndrome. Ophthalmic Genet 2010;31:94-97.

-3 Bosch-Valero J, Mateo J, Lavilla-García L, Núñez-Benito E, Cristóbal JA: Spontaneous closure of full thickness traumatic macular holes. Arch Soc Esp Oftalmol 2008;83:325-327.

4 Susini A, Gastaud P: Macular holes that should not be operated. J Fr Ophtalmol 2008;31:214-220. 